\title{
INCIDENCE OF ANENCEPHALUS, SPINA BIFIDA, AND HYDROCEPHALUS RELATED TO BIRTH RANK AND MATERNAL AGE*
}

\author{
BY \\ THEODORE H. INGALLS, THOMAS F. PUGH, AND BRIAN MACMAHON†
}

From the Department of Epidemiology, Harvard University School of Public Health, Boston, Mass., U.S.A.

\section{INTRODUCTION}

Several investigators have stressed the importance of genetic factors in the aetiology of malformations of the central nervous system, and some have even advanced hypotheses describing the genetic mechanisms involved. Such hypotheses are speculative, and the role of environmental events should continue to receive evaluation.

Association of characteristics of the offspring with birth order or with maternal age is provisional evidence of the operation of environmental influences in causation; in addition, such data may provide clues for the elucidation of the more specific environments involved. The weight of previously published evidence relating congenital malformations of the central nervous system to birth rank and maternal age suggests that both variables influence the occurrence of these anomalies. Penrose (1946), using a modification of the Greenwood-Yule method, found an increasing frequency of a group of central nervous malformations (anencephalus, spina bifida, and hydrocephalus) with advancing maternal age. After correction for the effect of maternal age, occurrence was somewhat excessive in the first birth rank and at birth ranks 7 and over. Malpas (1937) analysed the distribution of anencephaly (44 cases among 13,964 deliveries) according to maternal age, and found the defect to occur about ten times more frequently in the age group 46-50 than in the age group 16-20. Böök and Rayner (1950) surveyed the protocols of 67 cases of anencephaly without finding any significant relation of the defect to advancing age or birth rank. Schwidde (1952) and Polman (1950) have also reported negative findings. Büchi (1950) identified 2,922 malformed infants among some 160,000 births

\footnotetext{
* Supported by a grant from the Association for the Aid of Crippled Children, New York.

In receipt of a Rockefeller Foundation fellowship.
}

in Copenhagen, and noted increasing frequency of hydrocephalus, spina bifida, and anencephalus with increasing maternal age. A similar investigation by Hegnauer (1951) confirmed these relationships for hydrocephalus and anencephalus, although no association was observed between maternal age and spina bifida.

Record and McKeown (1949), presenting the largest material to date, compared stillbirths and infant deaths attributed to malformations of the central nervous system in Birmingham, England, with a sample of births in the general population. In their material, the effect of maternal age on anencephalus and spina bifida was slight when compared with the influence of birth order, incidence being relatively high in first births and in births after the sixth; the effect of birth order on hydrocephalus was slight compared with the marked increase with advancing maternal age.

\section{Material}

This study is concerned with all cases of anencephalus, spina bifida, and hydrocephalus recorded as having been delivered in the five large maternity units in the state of Rhode Island, U.S.A. during the years 1936-52. The percentage of births in the state which have occurred in these five units has increased over the period from 63.7 in 1936 to 74.4 in 1949 , the latest year for which figures are at hand. Over the whole period 1936-49. 67 per cent. of births in the state occurred in these hospitals. While it is a reasonable assumption that a patient with anticipated complications would be more likely to be delivered in one of these five hospitals than elsewhere in the state, their number is so diluted with normal deliveries that we believe the births occurring in these hospitals are reasonably representative of births in the central and northern sections of the state.

A comparison series was assembled by taking every one hundredth name from the delivery-room registers, which list confinements chronologically, for the same hospitals over the same period of time (1936-52), and by obtaining information on maternal age and parity from case records. 
TABLE I

PERCENTAGE DISTRIBUTION BY BIRTH RANK AND MATERNAL AGE OF COMPARISON GROUP, 1939-49 $(1,111)$, AND ALL LIVEBIRTHS TO RESIDENTS OF RHODE ISLAND, 1939-49 (151,977)

\begin{tabular}{|c|c|c|c|c|c|c|}
\hline \multirow{2}{*}{$\underset{\text { Age }}{\text { Maternal }}$} & \multicolumn{6}{|c|}{ Birth Rank } \\
\hline & 1 & 2 & 3 & 4 & $\begin{array}{l}5 \text { and } \\
\text { over }\end{array}$ & Total \\
\hline Under 20 & $\begin{array}{c}4 \cdot 95 \\
(4 \cdot 68)\end{array}$ & $\begin{array}{c}0.72 \\
(0.78)\end{array}$ & $\overline{(0.01)}$ & $\overline{(0.01)}$ & $=$ & $\begin{array}{c}5 \cdot 67 \\
(5 \cdot 57)\end{array}$ \\
\hline $20-24 \ldots$ & $\begin{array}{c}18 \cdot 81 \\
(18 \cdot 01)\end{array}$ & $\begin{array}{c}7 \cdot 38 \\
(7 \cdot 96)\end{array}$ & $\begin{array}{c}1 \cdot 62 \\
(2 \cdot 33)\end{array}$ & $\begin{array}{c}0.54 \\
(0.64)\end{array}$ & $(\overline{0 \cdot 24})$ & $\begin{array}{c}28 \cdot 35 \\
(29 \cdot 19)\end{array}$ \\
\hline $25-29 \ldots$ & $\begin{array}{c}12 \cdot 87 \\
(12 \cdot 52)\end{array}$ & $\begin{array}{c}11 \cdot 88 \\
(11 \cdot 21)\end{array}$ & $\begin{array}{c}4 \cdot 50 \\
(4 \cdot 95)\end{array}$ & $\begin{array}{c}1.35 \\
(1.99)\end{array}$ & $\begin{array}{c}1 \cdot 44 \\
(1 \cdot 51)\end{array}$ & $\begin{array}{c}32 \cdot 04 \\
(32 \cdot 18)\end{array}$ \\
\hline $30-34 \ldots$ & $\begin{array}{r}5 \cdot 94 \\
(4 \cdot 86)\end{array}$ & $\begin{array}{c}8 \cdot 10 \\
(6 \cdot 61)\end{array}$ & $\begin{array}{c}4 \cdot 95 \\
(4 \cdot 40)\end{array}$ & $\begin{array}{c}2 \cdot 34 \\
(2 \cdot 20)\end{array}$ & $\begin{array}{c}2 \cdot 25 \\
(2 \cdot 62)\end{array}$ & $\begin{array}{c}23 \cdot 58 \\
(20 \cdot 70)\end{array}$ \\
\hline $\begin{array}{l}35 \text { and } \\
\text { over }\end{array}$ & $\begin{array}{c}1 \cdot 17 \\
(1 \cdot 83)\end{array}$ & $\begin{array}{c}2 \cdot 97 \\
(2 \cdot 56)\end{array}$ & $\begin{array}{c}2 \cdot 52 \\
(2 \cdot 40)\end{array}$ & $\begin{array}{c}1 \cdot 26 \\
(1 \cdot 70)\end{array}$ & $\begin{array}{c}2 \cdot 43 \\
(3 \cdot 86)\end{array}$ & $\begin{array}{l}10 \cdot 35 \\
(12 \cdot 36)\end{array}$ \\
\hline Total .. & $\begin{array}{c}43 \cdot 74 \\
(41 \cdot 90)\end{array}$ & $\begin{array}{c}31 \cdot 05 \\
(29 \cdot 12)\end{array}$ & $\begin{array}{c}13 \cdot 59 \\
(14 \cdot 19)\end{array}$ & $\begin{array}{c}5 \cdot 49 \\
(6 \cdot 55)\end{array}$ & $\begin{array}{c}6 \cdot 12 \\
(8 \cdot 24)\end{array}$ & $\begin{array}{c}100 \cdot 0 \\
(100 \cdot 0)\end{array}$ \\
\hline
\end{tabular}

Data for all residents of Rhode Island in brackets.
Table I gives the percentage distribution by birth rank and maternal age of livebirths in the comparison group, and of livebirths $(151,977)$ to residents of Rhode Island occurring in the state during 1939-49, the years for which data are available from national vital statistics. Differences between the two distributions are small and support the belief that the comparison series is reasonably representative of births in the general population of Rhode Island.

\section{Birth Rank and Maternal Age}

Tables II and III compare the percentage distributions of the malformation and comparison series by birth rank and maternal age respectively. "Birth Rank" is calculated as the number of "viable" pregnancies; multiple births are counted once, and foetal deaths delivered before 5 completed months of gestation are excluded.

The grouped findings are in some respects similar to those reported by Record and McKeown (1949); an excess of malformations was found in first births and in birth ranks after the fifth, the percentage

TABLE II

PERCENTAGE DISTRIBUTION OF MALFORMATIONS AND COMPARISON GROUP BY BIRTH RANK

\begin{tabular}{|c|c|c|c|c|c|c|c|c|c|c|c|c|c|}
\hline \multicolumn{3}{|c|}{ Birth Rank } & \multicolumn{2}{|c|}{ Anencephalus } & \multicolumn{2}{|c|}{ Spina Bifida } & \multicolumn{2}{|c|}{ Hydrocephalus } & \multicolumn{2}{|c|}{$\stackrel{\text { All }}{\text { Malformations (a) }}$} & \multicolumn{2}{|c|}{$\begin{array}{l}\text { Comparison } \\
\text { Group (b) }\end{array}$} & \multirow{2}{*}{$\begin{array}{l}\text { Difference } \\
(a)-(b)\end{array}$} \\
\hline & & & No. & $\%$ & No. & $\%$ & No. & $\%$ & No. & $\%$ & No. & $\%$ & \\
\hline $1 \ldots$ & $\ldots$ & $\ldots$ & 150 & $46 \cdot 30$ & 201 & $47 \cdot 74$ & 68 & $44 \cdot 74$ & 419 & $46 \cdot 71$ & 699 & $42 \cdot 26$ & $+4.45 \pm 2.06^{*}$ \\
\hline $2 \ldots$ & . & .. & 87 & $26 \cdot 85$ & 106 & $25 \cdot 18$ & 34 & $22 \cdot 37$ & 227 & $25 \cdot 31$ & 509 & $30 \cdot 77$ & $-5.46 \pm 1.88$ \\
\hline $3 \ldots$ & .. & $\ldots$ & 42 & $12 \cdot 96$ & 57 & $13 \cdot 54$ & 20 & $13 \cdot 16$ & 119 & $13 \cdot 27$ & 233 & 14.09 & $-0.82 \pm 1.43$ \\
\hline 4 and 5 & $\ldots$ & .. & 28 & 8.64 & 39 & $9 \cdot 26$ & 22 & $14 \cdot 47$ & 89 & 9.92 & 152 & $9 \cdot 19$ & $+0.73 \pm 1 \cdot 21$ \\
\hline 6 and ove & & .. & 17 & $5 \cdot 25$ & 18 & $4 \cdot 28$ & 8 & $5 \cdot 26$ & 43 & $4 \cdot 79$ & 61 & 3.69 & $+1 \cdot 10 \pm 0.82$ \\
\hline Total & . & $\ldots$ & 324 & $100 \cdot 0$ & 421 & $100 \cdot 0$ & 152 & $100 \cdot 0$ & 897 & $100 \cdot 0$ & 1,654 & $100 \cdot 0$ & - \\
\hline
\end{tabular}

Birth rank was unknown for two anencephalics, five cases of spina bifida, and sixteen comparison patients.

* Difference exceeds twice its standard error.

TABLE III

PERCENTAGE DISTRIBUTION OF MALFORMATIONS AND COMPARISON GROUP BY MATERNAL AGE

\begin{tabular}{|c|c|c|c|c|c|c|c|c|c|c|c|c|}
\hline \multicolumn{2}{|c|}{ Maternal Age } & \multicolumn{2}{|c|}{ Anencephalus } & \multicolumn{2}{|c|}{ Spina Bifida } & \multicolumn{2}{|c|}{ Hydrocephalus } & \multicolumn{2}{|c|}{$\stackrel{\text { All }}{\text { Malformations (a) }}$} & \multicolumn{2}{|c|}{$\begin{array}{l}\text { Comparison } \\
\text { Group (b) }\end{array}$} & \multirow{2}{*}{$\begin{array}{l}\text { Difference } \\
(a)-(b)\end{array}$} \\
\hline & . & No. & $\%$ & No. & $\%$ & No. & $\%$ & No. & $\%$ & No. & $\%$ & \\
\hline Under 20 & .. & 21 & $6 \cdot 48$ & 20 & $4 \cdot 75$ & 2 & $1 \cdot 32$ & 43 & $4 \cdot 79$ & 84 & 5.08 & $-0.29 \pm 0.90$ \\
\hline $20-24$ & $\ldots$ & 85 & $26 \cdot 23$ & 103 & $24 \cdot 47$ & 45 & $29 \cdot 61$ & 233 & $25 \cdot 97$ & 479 & $28 \cdot 96$ & $-2 \cdot 99 \pm 1 \cdot 86$ \\
\hline $25-29$ & $\ldots$ & 110 & 33.95 & 147 & $34 \cdot 92$ & 39 & 25.66 & 296 & $33 \cdot 00$ & 519 & $31 \cdot 38$ & $+1.62 \pm 1.93$ \\
\hline $30-34$ & $\ldots$ & 66 & $20 \cdot 37$ & 88 & 20.90 & 30 & $19 \cdot 74$ & 184 & $20 \cdot 51$ & 386 & $23 \cdot 34$ & $-2 \cdot 83 \pm 1 \cdot 73$ \\
\hline $35-39$ & $\ldots$ & 31 & $9 \cdot 57$ & 46 & 10.93 & 29 & $19 \cdot 08$ & 106 & $11 \cdot 82$ & 156 & $9 \cdot 43$ & $+2 \cdot 39 \pm 1 \cdot 26$ \\
\hline 40 and over & . & 11 & $3 \cdot 40$ & 17 & 4.04 & 7 & $4 \cdot 61$ & 35 & 3.90 & 30 & $1 \cdot 81$ & $+2.09 \pm 0.65^{*}$ \\
\hline Total & $\ldots$ & 324 & $100 \cdot 0$ & 421 & $100 \cdot 0$ & 152 & $100 \cdot 0$ & 897 & $100 \cdot 0$ & 1,654 & $100 \cdot 0$ & - \\
\hline
\end{tabular}

* Difference exceeds twice its standard error. 
relative to the comparison group being lowest in second births (Table II). These differences are, however, less marked than those noted in Birmingham, particularly in the excess of malformations in the later birth ranks, an excess which is not significant in the present series. For the three malformations grouped, a significant excess of anomalies is observed at high maternal ages (Table III).

The Tables also show the percentage distributions by age and parity of mothers for each of the three main subdivisions of central nervous system anomalies. Anencephalus with spina bifida is classed as "anencephalus", and encephalocele or spina bifida with hydrocephalus as "spina bifida". We have previously shown that sex ratios of individual malformations do not contraindicate these groupings (MacMahon, Pugh, and Ingalls, 1953). We have also examined maternal age and birth order association separately for each of these five diagnoses and found no appreciable differences between anencephalus and anencephalus with spina bifida, or between spina bifida, spina bifida with hydrocephalus, and encephalocele. The small numbers involved in a finer subdivision, and the desirability of presenting material comparable to that previously published by others, are further reasons for adopting these groupings.

The excess of first births (Table II) is found to be mainly the result of excesses in the anencephalus and spina bifida groups, while the excess at high maternal ages (Table III) occurs almost entirely in the group of hydrocephalic infants. The percentage of mothers aged 35 years and over in the hydrocephalic group is $23 \cdot 7$, which differs from the corresponding percentage for the comparison group $(11 \cdot 2)$ by $12 \cdot 4 \pm 2 \cdot 8$ per cent.

In Tables IV, V, and VI, trends with age and parity are examined separately for the three diagnoses by calculating incidence according to age and parity simultaneously. The assumption is made that all births $(168,654)$ recorded in the five hospitals over the period of the inquiry are distributed by age and parity according to the distribution of the 1,654 mothers in the comparison group for whom age and parity were known.

The results are as might be expected from the data presented in Tables II and III. For both anencephalus (Table IV) and spina bifida (Table V) the main variation is in association with birth order.

TABLE IV

INCIDENCE OF ANENCEPHALUS PER 1,000 TOTAL BIRTHS RELATED TO BIRTH RANK AND MATERNAL AGE

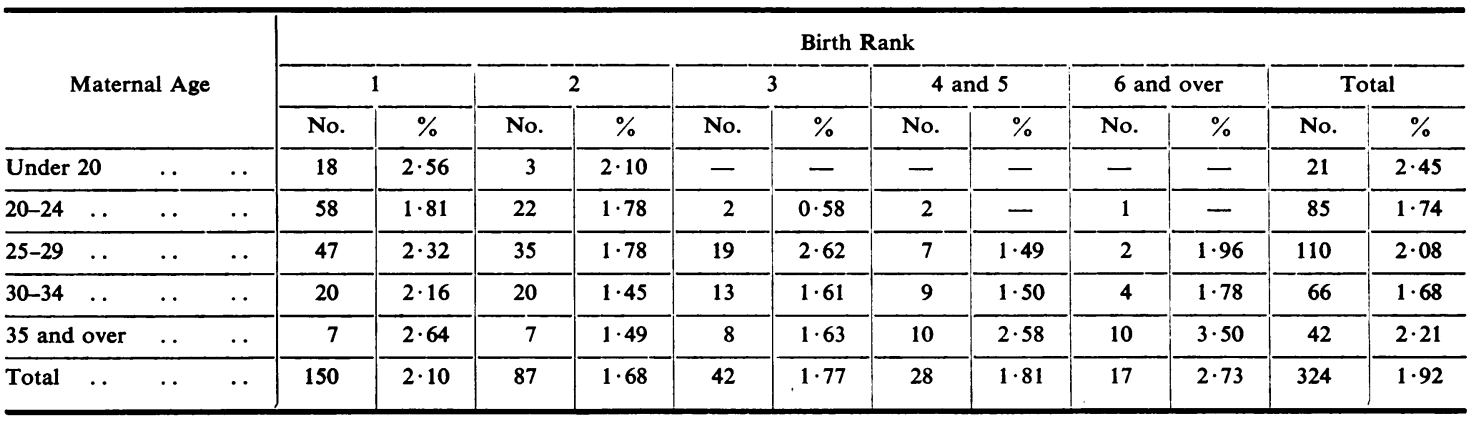

No estimates are given for cells containing less than 1,000 total births.

TABLE V

INCIDENCE OF SPINA BIFIDA PER 1,000 TOTAL BIRTHS RELATED TO BIRTH RANK AND MATERNAL AGE

\begin{tabular}{|c|c|c|c|c|c|c|c|c|c|c|c|c|c|c|}
\hline \multirow{3}{*}{\multicolumn{3}{|c|}{ Maternal Age }} & \multicolumn{12}{|c|}{ Birth Rank } \\
\hline & & & \multicolumn{2}{|c|}{1} & \multicolumn{2}{|c|}{2} & \multicolumn{2}{|c|}{3} & \multicolumn{2}{|c|}{4 and 5} & \multicolumn{2}{|c|}{6 and over } & \multicolumn{2}{|c|}{ Total } \\
\hline & & & No. & $\%$ & No. & $\%$ & No. & $\%$ & No. & $\%$ & No. & $\%$ & No. & $\%$ \\
\hline Under 20 & $\ldots$ &.. & 17 & $2 \cdot 42$ & 3 & $2 \cdot 10$ & - & - & - & - & 一 & 一 & 20 & $2 \cdot 33$ \\
\hline $20-24$ & . & $\ldots$ & 76 & $2 \cdot 37$ & 22 & $1 \cdot 78$ & 4 & $1 \cdot 15$ & 1 & - & - & - & 103 & $2 \cdot 11$ \\
\hline $25-29$ & .. & $\ldots$ & 65 & $3 \cdot 20$ & 42 & $2 \cdot 13$ & 27 & $3 \cdot 73$ & 11 & $2 \cdot 34$ & 2 & $1 \cdot 96$ & 147 & $2 \cdot 78$ \\
\hline $30-34$ & $\ldots$ & $\ldots$ & 29 & $3 \cdot 13$ & 24 & $1 \cdot 74$ & 18 & $2 \cdot 23$ & 14 & $2 \cdot 33$ & 3 & $4 \cdot 99$ & 88 & $2 \cdot 24$ \\
\hline 35 and over & . &. & 14 & $5 \cdot 28$ & 15 & $3 \cdot 20$ & 8 & $1 \cdot 63$ & 13 & $3 \cdot 35$ & 13 & $4 \cdot 55$ & 63 & $3 \cdot 32$ \\
\hline Total & .. & . & 201 & $2 \cdot 82$ & 106 & $2 \cdot 04$ & 57 & $2 \cdot 31$ & 39 & $2 \cdot 52$ & 18 & $2 \cdot 89$ & 421 & $2 \cdot 50$ \\
\hline
\end{tabular}


TABLE VI

INCIDENCE OF HYDROCEPHALUS PER 1,000 TOTAL BIRTHS RELATED TO BIRTH RANK AND MATERNAL AGE

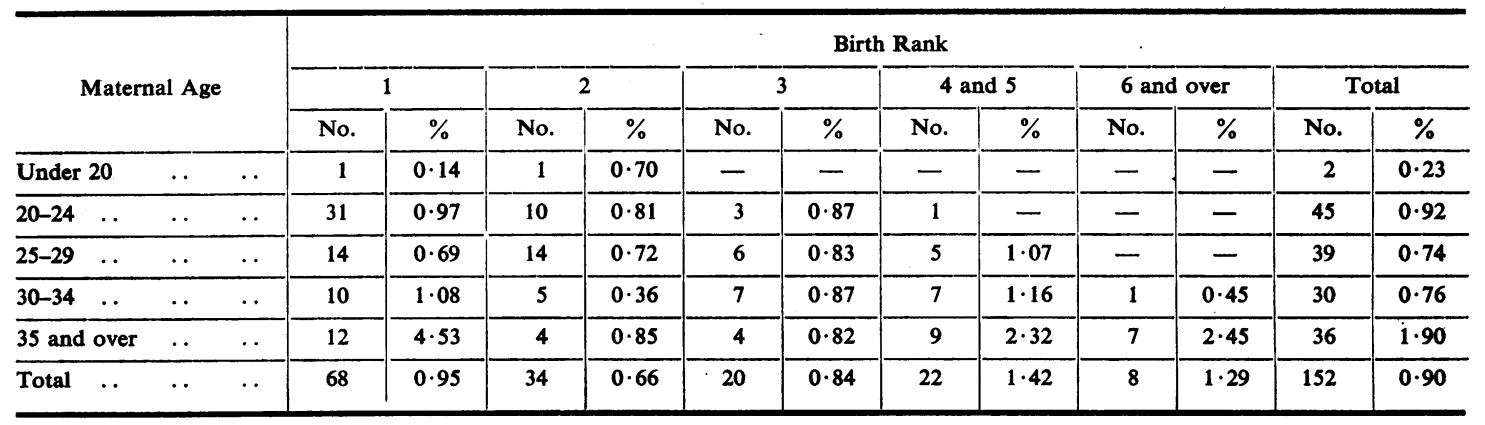

Incidence is high in first births, falls to its lowest level in second births, and then increases with increasing birth rank. Considering the small numbers involved, this trend is reasonably regular within each maternal age group. At the same time, incidence also varies, but to a lesser degree, with maternal age. Both in individual birth ranks and in the total for all birth ranks, there is a tendency for incidence, especially that of spina bifida, to be highest in the youngest and oldest mothers. The high incidence of spina bifida in first births at ages 35 and over is noteworthy. The reverse is found for hydrocephalus (Table VI), where the main variation is in association with maternal age, but where there is nevertheless a tendency for incidence to be highest in first and in fourth and later births. Here again the high incidence (five times the average incidence) in first births at ages 35 and over is noticeable. However, the data on hydrocephalus should be interpreted with caution, since criteria of diagnosis of this malformation lack clarity. Difficult labour is known to be more common at high maternal ages, particularly in primiparae, and it is conceivable that the diagnosis of hydrocephalus is made more frequently in difficult than in normal deliveries. To test this possibility, the 31 most severe cases were analysed separately, and in only four (13 per cent.) of them were the mothers aged 35 years or older. These numbers are admittedly small, but there appears to be little association with maternal age for this severe group.

\section{FAMILY Size}

Maternal fertility is an important consideration wherever an association with birth order or maternal age has been demonstrated. Available data permit only a limited consideration of family size, since dates of birth of previous siblings were available for only a small number of propositi.

The largest hospital from which our material is drawn (accounting for 53.1 per cent. of the malformation propositi and 52.5 per cent. of the controls) maintains a unit record system in which records for all admissions of each patient are included in one file. Available therefore, for mothers of malformation and control propositi born in that hospital, are the numbers of infants born subsequently in the same hospital (Table VII). The Table is limited to first-born propositi and siblings born subsequently until 1st October, 1952; propositi born in 1952 are excluded since none had siblings born in that year.

TABLE VII

PERCENTAGE DISTRIBUTION ACCORDING TO NUMBER OF SUBSEQUENT SIBLINGS BORN IN THE SAME HOSPITAL

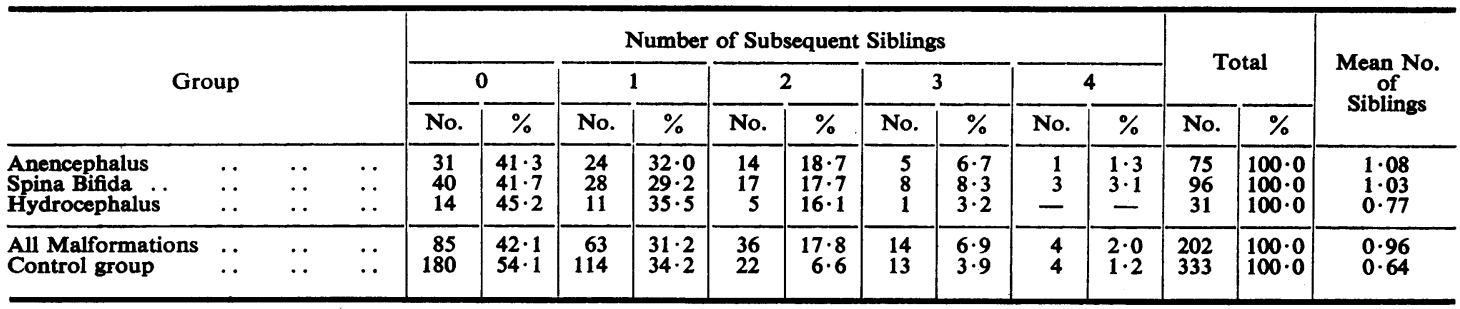

Comparing all malformations with controls (grouping 3 and 4): $x^{2}=21 \cdot 37, n=3, p<0 \cdot 01$.

Table, based on firstborn propositi in one hospital, 1936-51, refers to subsequent siblings born before October 1, 1952. 
The data suggest that mothers of malformed children have more children subsequently than mothers of normal children, but this cannot be inferred with confidence since the total family structure remains unverified. Nevertheless, it seems reasonable to suppose that at least a part of the excess of children born to mothers of malformations may be explained by a greater desire for subsequent children when the first is dead or grossly deformed. Such evidence as we have, therefore, indicates no limitation of family size following a firstborn child with one of the central nervous system anomalies considered here, and the low incidence of anencephalus and spina bifida in births immediately following the first is not explainable on the basis of such limitation. Record and McKeown (1950) found no significant difference in fertility between mothers of malformed infants and mothers of control infants.

During the course of the inquiry, positive statements of maternal illnesses appearing on the obstetric case records of mothers of malformed infants were noted; such data are of wholly speculative value, since completeness of recording of such events is not known: no instance of rubella was recorded; three mothers had appendectomy during pregnancy, two in the first trimester and one on an unrecorded date; two had bicornuate uteri and one a septate vagina; four had placenta praevia; one had measles in the first month of pregnancy; and a diabetic mother gave birth to two successive macerated foetuses with hydrocephalus and a third child suspected of having congenital heart disease. Such observations must be viewed against the background of the 904 births among which they occurred. No significance can be attached to them in the absence of an unbiased search for similar events in the control group. None the less, they are worthy of record, since congenital anencephalus, spina bifida, and hydrocephalus have been induced experimentally of late years by such diverse environmental insults to the mother as roentgen irradiation (Russell, 1950), vitamin deficiencies (Warkany, 1945), trypan-blue intoxication (Gillman and others, 1948), or anoxia (Ingalls and others, 1950).

\section{Discussion}

The results of this investigation are in general agreement with those of Record and McKeown carried out in Birmingham, England. It is of interest, however, to speculate on certain differences in the findings of the two series, and on how these may have arisen. The association between hydrocephalus and maternal age is similar in both studies, but the association of birth order with anencephalus and spina bifida, while similar in trend, is less marked in the Rhode Island data.

The Rhode Island series has advantages in respect of accuracy of diagnosis and completeness of information on birth order and maternal age since the source of clinical information at Birmingham was death certificates. On the other hand, the Birmingham study has advantages in that it was not limited to hospital deliveries. All the implications of these selective features are not clear, but certain obvious factors may have contributed to the differences noted.

For example, the percentage of first births in our comparison group is slightly higher than that in all livebirths to residents of Rhode Island (Table I). The difference is small and not significant $(1.84 \pm 1.48)$ but is nevertheless fairly constant throughout the period covered, and it seems reasonable to believe that a hospital population may be selected in favour of first births. On the other hand, births involving malformed infants, in common with other difficult or abnormal labours, may not be selected for parity to the same degree, and may be more representative of the population as a whole. This would tend to lower the incidence of malformations in hospital first births. If this were true the influence would be small, since the effect of using the Rhode Island livebirth figures instead of the hospital control population would be to raise the incidence of anencephalus in first births from $2 \cdot 10$ to $2 \cdot 12$ per cent., and of spina bifida from $2 \cdot 82$ to $2 \cdot 84$ per cent. More likely the difference between the comparison group and Rhode Island live births results from the absence of stillbirths, known to be commoner in first births, in the latter group. We have no information on survival for the hospital comparison group or on stillbirths for Rhode Island residents, and therefore cannot make a direct comparison.

Another feature of selection which probably influences the lower incidence of malformations observed in first births in Rhode Island is the relationship between duration of gestation and probability of being delivered in hospital. Duration of the gestation terminating in the birth of an infant with anencephalus is not given in the Birmingham series for the years of the age and parity inquiry, but is given in another communication for a somewhat longer period (MacMahon and McKeown, 1952). These data are reproduced in Table VIII (overleaf), with similar figures for Rhode Island. There are significantly fewer anencephalics of short gestation in the Rhode Island series. Anencephalics of short gestation are more commonly first born than are those of later gestation (MacMahon and McKeown, 1952), and a deficiency of early gestations 
TABLE VIII

PERCENTAGE DISTRIBUTION OF CASES OF ANENCEPHALUS BY DURATION OF GESTATION FOR BIRMINGHAM (1940-51)* AND RHODE ISLAND (1936-52)

\begin{tabular}{|c|c|c|c|c|c|c|c|c|c|c|}
\hline \multirow{3}{*}{\multicolumn{2}{|c|}{ Investigation }} & & \multicolumn{6}{|c|}{ Duration of Gestation (wks) } & \multirow{2}{*}{\multicolumn{2}{|c|}{ Total }} \\
\hline & & & \multicolumn{2}{|c|}{ Under 33} & \multicolumn{2}{|c|}{ 33-37 } & \multicolumn{2}{|c|}{38 and over } & & \\
\hline & & & No. & Per cent. & No. & Per cent. & No. & Per cent. & No. & Per cent. \\
\hline Birmingham & $\cdots$ & . & 139 & $29 \cdot 3$ & 194 & $40 \cdot 8$ & 142 & $29 \cdot 9$ & 475 & $100 \cdot 0$ \\
\hline Rhode Island & $\cdots$ & $\cdots$ & 69 & $22 \cdot 6$ & 130 & $42 \cdot 6$ & 106 & $34 \cdot 8$ & $305 t$ & $100 \cdot 0$ \\
\hline Difference & $\cdots$ & $\cdots$ & & $6 \cdot 7 \pm 3 \cdot 2$ & & $1 \cdot 8 \pm 3 \cdot 6$ & & $4 \cdot 9 \pm 3 \cdot 4$ & & - \\
\hline
\end{tabular}

*Data from MacMahon and McKeown (1952).

†Duration of gestation not known for 21 anencephalic births.

TABLE IX

PERCENTAGE DISTRIBUTION OF ANENCEPHALICS BY BIRTH RANK ACCORDING TO DURATION OF GESTATION FOR BIRMINGHAM (1940-51)*, and RHODE ISLAND (1936-52).

\begin{tabular}{|c|c|c|c|c|c|c|}
\hline \multirow{2}{*}{ Investigation } & \multirow{2}{*}{ Birth Rank } & \multicolumn{4}{|c|}{$\begin{array}{l}\text { Anencephalus } \\
\text { Duration of Gestation (wks) }\end{array}$} & \multirow{2}{*}{ Comparison Groupt } \\
\hline & & Under 33 & $33-37$ & 38 and over & Total & \\
\hline \multirow[t]{2}{*}{ Birmingham } & $\begin{array}{c}1 \\
2 \\
3 \\
4 \text { and over }\end{array}$ & $\begin{array}{r}66 \cdot 9 \\
16 \cdot 5 \\
6 \cdot 5 \\
10 \cdot 1\end{array}$ & $\begin{array}{r}51 \cdot 8 \\
22 \cdot 3 \\
8 \cdot 3 \\
17 \cdot 6\end{array}$ & $\begin{array}{l}35 \cdot 5 \\
24 \cdot 8 \\
14 \cdot 9 \\
24 \cdot 8\end{array}$ & $\begin{array}{r}51 \cdot 4 \\
21 \cdot 4 \\
9 \cdot 7 \\
17 \cdot 5\end{array}$ & $\begin{array}{l}34 \cdot 0 \\
29 \cdot 8 \\
15 \cdot 0 \\
21 \cdot 3\end{array}$ \\
\hline & Total & $\begin{array}{c}100 \\
(139)\end{array}$ & $\begin{array}{c}100 \\
(193)\end{array}$ & $\begin{array}{l}100 \\
(141)\end{array}$ & $\begin{array}{l}100 \\
(473)\end{array}$ & $\begin{array}{l}100 \ddagger \\
(742)\end{array}$ \\
\hline \multirow[t]{2}{*}{ Rhode Island } & $\begin{array}{c}1 \\
2 \\
3 \\
4 \text { and over }\end{array}$ & $\begin{array}{l}59 \cdot 4 \\
18 \cdot 8 \\
10 \cdot 1 \\
11 \cdot 6\end{array}$ & $\begin{array}{l}42 \cdot 3 \\
29 \cdot 2 \\
13 \cdot 8 \\
14 \cdot 6\end{array}$ & $\begin{array}{l}43 \cdot 4 \\
28 \cdot 3 \\
13 \cdot 2 \\
15 \cdot 1\end{array}$ & $\begin{array}{l}46 \cdot 6 \\
26 \cdot 6 \\
12 \cdot 8 \\
14 \cdot 1\end{array}$ & $\begin{array}{l}42 \cdot 3 \\
30 \cdot 8 \\
14 \cdot 1 \\
12 \cdot 9\end{array}$ \\
\hline & Total & $\begin{array}{l}100 \\
(69)\end{array}$ & $\begin{array}{c}100 \\
(130)\end{array}$ & $\begin{array}{r}100 \\
(106)\end{array}$ & $\begin{array}{l}100 \\
(305)\end{array}$ & $\begin{array}{r}100 \\
(1,654)\end{array}$ \\
\hline
\end{tabular}

*Data from MacMahon and McKeown (1952).

†Data from Record and McKeown (1949). The years are not exactly comparable.

$\ddagger$ Actual numbers in brackets.

could therefore account for a low proportion of first births in the series. In this respect Table IX is of interest. If the inquiries had been confined to anencephalics of relatively long gestation (in Birmingham 38 weeks or over, in Rhode Island hospitals 33 weeks or over), no relationship between primiparity and anencephalus would have been found. As an explanation of the difference between the incidence in first births in the two series, this situation depends on a relationship between early onset of labour and domiciliary delivery. No such relationship was found for all births in Birmingham by Gibson and McKeown (1950), but this does not deny the possibility of its existence for anencephalics in Rhode Island. Such considerations do not apply to cases of spina bifida, in which early onset of labour is unusual.

Differences in the lengths of time covered in the two inquiries may also have contributed to the differences in birth order incidence. Both in Birmingham and in Rhode Island the incidence of anencephalus and spina bifida was appreciably lower during the late 1940s, than during the war years. While the Birmingham age and parity inquiry was limited to the years of highest incidence, the Rhode Island survey covered a wider period.

Table $X$ (opposite) gives the incidence of anencephalus and spina bifida combined in 4-yearly periods. The secular change in incidence noted in our previous communication (MacMahon, Pugh, and Ingalls, 1953) was most marked in first births, with the consequence that difference in incidence between first and later births was most marked in the earlier years of the inquiry. In fact, for the period $1948-52$, no increased incidence in first births is observed. This situation is seen for both anencephalus and spina bifida when these are examined separately. Thus, if the inquiry had not included the years 1948-52, the results would have indicated a greater excess of first births than that now noted.

None of these considerations accounts for the lower incidence in later birth ranks here noted 
TABLE X

INCIDENCE OF ANENCEPHALUS AND SPINA BIFIDA COMBINED BY BIRTH ORDER IN FOUR YEARLY TIME PERIODS

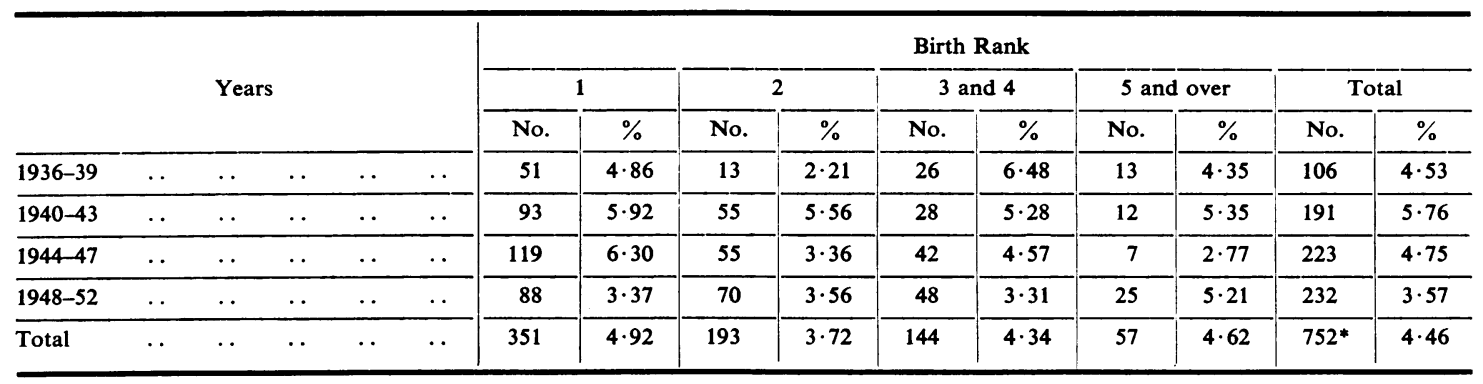

*Includes seven cases of unknown birth order.

relative to the Birmingham study, and for this difference we have no explanation.

Interpretation of the meaning of these birth rank and maternal age associations is difficult. They may reasonably be regarded as evidence of the influence of environment in the aetiology of the conditions. The observation that the association between primiparity and anencephalus and spina bifida has been subject to secular change might suggest that the relationship has its explanation in the social and physical environment of the mother rather than in anatomic or physiological changes connected with birth order.

\section{SUMMARY}

Information on birth rank and maternal age is available for 324 cases of anencephalus, 421 cases of spina bifida, 152 hydrocephalics, and 1,654 comparison births occurring in the five large maternity units in the state of Rhode Island during the years 1936-52.

For anencephalus and spina bifida, incidence falls from Birthrank 1 to Birthrank 2, and then increases progressively with birth order. For hydrocephalus, incidence increases progressively with maternal age. Less marked associations are noted with birth order for hydrocephalus, and with maternal age for anencephalus and spina bifida.

For anencephalus, the high incidence in first births is limited to those of short gestation. For both anencephalus and spina bifida the association with primiparity is most marked in the early years of the study and is in fact non-existent in the period 1948-52. This is interpreted as evidence that the association with primiparity results from social or external environmental factors.

Data on maternal fertility are limited, but suggest that there is no family limitation following a first-born malformed infant.

We are indebted to the administrative and obstetric staffs of the Pawtucket Memorial, Providence Lying-In, Roger Williams General, St. Joseph's, and Woonsocket General Hospitals, who kindly gave access to their records.

We are particularly grateful for the encouragement of Drs. Harmon P. Jordon, Alfred L. Potter, Walter S. Jones, and John G. Walsh, and of Miss Gertrude Cahir, of the Providence Lying-In Hospital, where the study was begun.

\section{REFERENCES}

Böök, J. A., and Rayner, S. (1950). Amer. J. hum. Genet., 2, 61.

Büchi, E. C. (1950). Arch. Klaus-Stift. VererFborsch., 25, 61.

Gibson, J. R., and McKeown, T. (1950). British Journal of Social Medicine, 4, 221.

Gillman, J., Gilbert, C., and Gillman, T. (1948). S. Afr. J. med. Sci., $13,47$.

Hegnauer, H. (1951). Geburts. u. Frauenheilk., 11, 777.

Ingalls, T. H., Curley, F. J., and Prindle, R. A. (1950). Amer. J. Dis. Child., 80, 34.

MacMahon, B., and McKeown, T. (1952). British Journal of Social

Medicine, 6, 265.
Pugh, T. F., and Ingalls, T. H. (1953). British Journal of Preventive and Social Medicine, 7, 211 .

Malpas, P. (1937). J. Obstet. Gynaec. Brit. Emp., 44, 434.

Penrose, L. S. (1946). Ann. Eugen., Camb., 13, 73.

Polman, A. (1950). Genetica, 25, 29.

Record, R. G., and McKeown, T. (1949). British Journal of Social Medicine, 3, 183.

Medicine, 3, 183. Ibid., 4, 26.

Russell, L. B. (1950). J. Exp. Zool., 114, 545.

Schwidde, J. T. (1952). Amer. J. Dis. Child., 84, 35.

Warkany, J. (1945). Vitam. and Horm., 3, 73. 